\title{
Influência da profundidade do úbere na limpeza dos tetos e na saúde da glândula mamária em ordenha robótica
}

[Influence of udder depth on cleaning teats and health of the mammary gland in robotic milking]

\author{
H.A. Córdova ${ }^{1}$, L.L. Cardozo ${ }^{2}$, D.R.M. Alessio ${ }^{2}$, A. Thaler Neto ${ }^{2}$
}

${ }^{1}$ Secretaria de Estado da Educação do Paraná - Rio Negro, PR

${ }^{2}$ Universidade do Estado de Santa Catarina - Lages, SC

\begin{abstract}
RESUMO
O objetivo deste trabalho foi avaliar a influência da profundidade do úbere sobre a limpeza de tetos e a saúde da glândula mamária. O experimento foi desenvolvido no período de março a junho de 2014, em Castro, PR. Foram utilizadas 20 vacas da raça Holandesa confinadas em free stall e ordenhadas em sistema de ordenha robotizada (SOR). As vacas foram divididas em quatro grupos com cinco animais cada (duas primíparas e três multíparas), com base na distância do piso do úbere em relação ao jarrete (úbere profundo, normal, pequeno e raso). Os dados, registrados eletronicamente, foram coletados mensalmente, por quatro meses, referentes à semana do controle leiteiro oficial. Para avaliar a efetividade da limpeza dos tetos, foram feitos swabs de dois tetos contralaterais (anterior direito e posterior esquerdo) antes e após a limpeza automática, bem como foram esfregadas toalhas umedecidas, uma vez, ao redor dos outros tetos. Uma amostra de leite foi coletada por vaca para determinar a contagem de células somáticas (CCS). Na análise multivariada, foi observada relação da profundidade do úbere com a limpeza de tetos avaliada por meio do escore de limpeza de tetos com toalhas umedecidas (ELTT). Os úberes levemente acima do jarrete (normal) apresentaram menor CCS e contagem bacteriana total (CBT) dos tetos. Os úberes rasos apresentaram maior diferença no ELTT. As vacas com úberes profundo e raso apresentaram menor efetividade na limpeza de tetos e na saúde da glândula mamária. Vacas com úbere normal apresentaram conformação e sanidade da glândula mamária e contaminação de tetos mais adequadas à ordenha robótica. Em fazendas que pretendem introduzir o SOR, é recomendado selecionar vacas com úbere com profundidade um pouco acima do jarrete. O impacto do SOR na CBT dos tetos está relacionado à condição de limpeza deles na pré-ordenha e das instalações. Portanto, a condição de ambiência das vacas é fundamental para a saúde da glândula mamária e a obtenção de um leite com alta qualidade.
\end{abstract}

Palavras-chave: ordenha robótica, produção de leite, limpeza de tetos, profundidade do úbere

\begin{abstract}
The aim of this study was to assess the influence of the depth of the udder on cleaning of teats and health of the mammary gland. The experiment was developed in the period spanning from March to June 2014, in Castro, PR. Twenty Holstein cows confined in free stall and milked in an automatic milking system (AMS) were used. The cows were divided into 4 groups with five animals ( 2 primiparous and 3 multiparous) based on the depth of the udder (udder depth: normal, small, and shallow). The electronically recorded data were collected monthly for four months, referring to the week of the official production milk control. To evaluate the effectiveness of cleaning teats, two contralateral teats were swabbed (right front quarter and left rear) before and after the automatic cleaning and once moistened towels were scrubbed around the other teats. A sample of milk was collected per cow to determine the somatic cell count (SCC). In the multivariate analysis relation of the udder depth with the teat cleaning was observed and evaluated through the teat cleaning with moistened towels score (TCTS). Udders slightly above the hocks (normal) had lower SCC and total bacterial count (TBC) of the teats. Shallow udders showed greater difference in TCTS. Cows with deep and shallow udders show less effective teat cleaning and health of the mammary gland. Cows with normal udders presented mammary gland conformation and health and contamination of teats most appropriate for robotic milking. On farms intending to introduce AMS it is recommended to select cows with udder depth which is a little above the hock. The impact of AMS on the TBC of the teats is related to the condition of cleaning of the teats pre-milking and
\end{abstract}

Recebido em 14 de setembro de 2016

Aceito em 22 de novembro de 2017

E-mail: a8hac@yahoo.com.br 
housing conditions. Therefore, the condition of ambience of the cows is fundamental for the health of the mammary gland and obtaining high quality milk.

Keywords: milking robotic, milk production, teats cleaning, udder depth

\section{INTRODUÇÃO}

A introdução do sistema de ordenha robotizada (SOR) é acompanhada de mudanças nas instalações, no método de limpeza de tetos, no agrupamento das vacas, no manejo dos dejetos, no melhoramento genético e no gerenciamento do rebanho. A uniformidade da conformação do úbere é uma característica relevante para um bom funcionamento da ordenha robótica. Os fabricantes do SOR definiram critérios de seleção que excluem vacas com dimensões de úbere $\mathrm{e}$ tetos inadequadas ao sistema. As dimensões mais importantes são distância do úbere em relação ao piso e tamanho e posição dos tetos (Miller et al., 1995). Posições e formas incorretas de tetos e lesões, bem como úberes grandes e profundos, facilitam a transmissão, penetração e multiplicação bacteriana (Janzekovic et al., 2009). Ainda, em vacas com úberes profundos ou muito grandes e/ou com tetos muito fechados, poderá haver dificuldade na colocação das teteiras (Carlström, 2014). No SOR, as dimensões do úbere e dos tetos para cada vaca podem ser armazenadas em um banco de dados, visando ao acoplamento do conjunto de ordenha pelo sistema. Embora a seleção para úberes mais adequados para a ordenha convencional venha sendo feita, ainda ocorre muita variação relacionada à variabilidade genética (Miller et al., 1995). Segundo esses autores, a idade, o estágio de lactação e outros fatores fazem com que algumas vacas apresentem comportamento ou aspectos da conformação do úbere inadequados para integrar o SOR.

A tradicional linha de ordenha, em que as vacas infectadas são ordenhadas por último, no SOR, é substituída pela limpeza dos insufladores com vapor de água quente entre vacas. Isso torna essencial o manejo de todo o sistema para evitar que o equipamento seja responsável pela transmissão de infecções intramamárias (IIM) entre vacas (Hovinen e Pyörälä, 2011). Segundo esses autores, a contaminação cruzada entre tetos é inibida, porém a transferência de bactérias entre vacas pode acontecer pela unidade de ordenha.
Como, durante a ordenha, os patógenos podem contaminar os tetos, a higiene tem um efeito fundamental na saúde da glândula mamária. No SOR, tetos sujos antes da ordenha constituem fator de risco para o aumento tanto de novos casos de IIM quanto da contagem de células somáticas (CCS) no rebanho (Dohmen et al., 2010). Knappstein et al. (2004) e Hovinen et al. (2005) observaram grandes diferenças na limpeza antes e depois da higienização dos tetos, as quais são decorrentes dos diversos sistemas de higienização dos tetos utilizados no SOR. Comum a todos é a inexistência de controle da efetividade na limpeza dos tetos. Knappstein et al. (2004) constataram diferenças significativas na eficiência de limpeza dos tetos das variadas marcas de SOR ao mensurarem a contagem bacteriana total (CBT).

O escore de limpeza do úbere e dos tetos fornece um indicador útil do desafio ambiental sobre a sanidade da glândula mamária e é fundamental para programas de garantia da qualidade do leite. Vários fatores contribuem para as rotas de contaminação dos tetos, como alimentos contaminados, material das camas e uso de raspadores mecânicos (Magnusson, 2007). O escore de limpeza dos tetos é uma ferramenta útil para monitorar a limpeza e a higiene das instalações, a fim de se reduzirem as IIM e a CCS.

Para superar os problemas acima expostos, pesquisas detalhadas e experiências práticas sobre limpeza de tetos e conformação de úbere poderão revelar quais características exteriores dos animais o SOR requer para maior produtividade e qualidade do produto final. Aliado a isso, existem poucos trabalhos reportando o impacto da profundidade do úbere na limpeza de tetos e na sanidade da glândula mamária nesse sistema.

O objetivo deste trabalho foi relacionar a profundidade do úbere com a limpeza e a contaminação de tetos e com a saúde da glândula mamária. 


\section{MATERIAL E MÉTODOS}

O experimento foi desenvolvido em uma propriedade com SOR, localizada em Castro, PR (244' $10^{\prime \prime}$ de latitude sul, 49 $50^{\prime} 57^{\prime \prime}$ de longitude oeste e $988 \mathrm{~m}$ de altitude), no período de março a junho de 2014. Os dados foram coletados de 20 vacas da raça Holandesa, oito primíparas e 12 multíparas, confinadas em free stall e ordenhadas automaticamente. As vacas foram distribuídas em quatro grupos de cinco animais (duas primíparas e três multíparas), de acordo com a distância do piso do úbere em relação ao jarrete (1 - úbere profundo, 2 normal, 3 - pequeno e 4 - raso), homogêneos em paridade e dias em lactação (DEL). Informações de paridade e DEL para a formação dos grupos foram obtidas do software de gerenciamento (DelPro $^{\mathrm{TM}}$, DeLaval, Tumba, Suécia) do Voluntary Milking System (VMSTM, DeLaval, Tumba, Suécia). A distância do piso do úbere em relação ao jarrete foi avaliada antes da ordenha, conforme metodologia descrita por Klaas et al. (2005). Os úberes com piso acima da metade da distância entre o nível do jarrete e a prega do flanco foram classificados como raso; pequeno: piso acima do jarrete e abaixo da metade da distância entre a prega do flanco e o jarrete; normal: piso com altura ao nível do jarrete; e profundo: piso abaixo do nível do jarrete. Durante o estudo, três vacas foram substituídas, uma por deslocamento de abomaso, outra por morte e a outra por elevada CCS. No início das avaliações, as vacas apresentavam, em média, $1,7 \pm 0,65$ partos, estavam com DEL de $131,6 \pm 63,42$ dias, eram ordenhadas $2,4 \pm 0,44$ vezes ao dia e produziam $38,8 \pm 9,69 \mathrm{~kg}$ de leite/dia.

Os dados foram coletados mensalmente, por quatro meses, na semana da realização do controle leiteiro oficial. Os dados referentes à CCS do leite foram obtidos, mensalmente, com base em relatórios do controle leiteiro oficial. $\mathrm{Na}$ análise estatística, foram consideradas as médias de sete dias para as variáveis produção de leite e número de ordenhas diárias, registradas pelo software de gerenciamento.

Para avaliar a eficácia na limpeza dos tetos, foram coletados swabs da parte anterior de dois tetos contralaterais (anterior direito e posterior esquerdo) antes da limpeza automática; logo após, foram coletados swabs da parte lateral externa dos mesmos tetos. Na coleta de swabs, foram utilizados frascos plásticos com tampa rosqueada com meio de transporte e hastes de plástico com algodão estéril, as quais foram friccionadas na superfície dos tetos, com movimentos rotativos, antes da limpeza deles pelo braço robótico e 30 segundos após a limpeza. Em seguida, os swabs foram colocados em tubos com $10 \mathrm{~mL}$ de meio de transporte composto por $0,07 \%$ de lecitina de soja purex, $0,5 \%$ de extrato de carne, $0,5 \%$ de cloreto de sódio, $1 \%$ de proteose peptone e $0,5 \%$ de Tween 80. Os frascos foram mantidos refrigerados, em caixa de isopor com gelo, até o início da análise, na manhã seguinte. A metodologia utilizada para coleta de swabs e CBT da pele dos tetos, em unidades formadoras de colônias $/ \mathrm{mL}$ ( $\mathrm{ufc} / \mathrm{mL}$ ), seguiu as normas estabelecidas pelo National Mastitis Council (Microbiological..., 2004), e a coleta foi realizada no laboratório Labvet, Carambeí, PR.

Antes e após à limpeza dos tetos, também foi avaliado o escore de limpeza dos tetos com toalhas umedecidas (ELTT), esfregando-se as toalhas (HIGICOW ${ }^{\circledR}$, RuralBan, Nova Friburgo, $\mathrm{RJ})$ uma vez ao redor de dois tetos contralaterais (anterior esquerdo e posterior direito), da base para a extremidade deles. Após a amostragem, as toalhas foram secas à temperatura ambiente $\mathrm{e}$ classificadas, visualmente, por meio de escore 0 (sem sujidade visível) a 4 (extremamente sujas), sendo considerada a área suja da toalha e a espessura da sujidade conforme descrito por Hovinen (2009).

$\mathrm{Na}$ realização do controle leiteiro oficial, uma amostra de leite da ordenha da manhã foi coletada de todos os quartos mamários em conjunto, mediante uso do coletor automático de amostras (Shuttle, DeLaval,Tumba, Suécia), em frascos-padrão para coleta, que continham conservante Bronopol ${ }^{\circledR}$, (2-bromo-2nitropropano-1,3-diol). Após, essas amostras foram encaminhadas ao Laboratório do Programa de Análises de Rebanhos Leiteiros do Paraná (PARLPR) da Associação Paranaense de Criadores de Bovinos da Raça Holandesa (APCBRH), em Curitiba, PR, para determinação dos teores de proteína e gordura e CCS. As metodologias absorção infravermelha, realizada em equipamento Bentley 2000 ${ }^{\mathrm{TM}}$ (Bentley Instruments Inc., Chasca, MN, USA), seguindo as recomendações da International Dairy 
Federation (International..., 1996) $141^{\circ} \mathrm{C}$, e citometria de fluxo em equipamento Somacount $500^{\mathrm{TM}}$ (Bentley Instruments Inc., Chasca, MN, USA), conforme o protocolo para leite cru ISO 13366-2, 148-2 (International..., 2005), foram utilizadas, respectivamente, para analisar os teores de gordura e proteína e CCS.

Os dados foram avaliados por técnicas de análise multivariada (análise fatorial, canônica e de agrupamento), utilizando-se o pacote estatístico SAS (1999), e foram previamente padronizados pelo procedimento padrão (PROC STANDARD). Os dados de CCS foram transformados em escore de células somáticas $\left(\mathrm{ECS}=\log _{2}(\mathrm{CCS} / 100)+3\right)$ (Ali e Shook, 1980), e as contagens bacterianas resultantes dos swabs, expressas em $\mathrm{ufc} / \mathrm{mL}$, foram transformadas em logaritmo na base 10. As variáveis ELTT e CBT, antes e depois da limpeza, e a diferença entre ambas (limpeza depois menos a limpeza antes) foram obtidas pela média dos dois tetos contralaterais avaliados antes e depois da limpeza.

A análise fatorial foi utilizada para avaliar a relação entre as variáveis, a fim de se reduzir o conjunto original de variáveis em um número menor de fatores, compondo-se cada fator pelas variáveis mais relacionadas entre si. A análise fatorial foi realizada pelo procedimento FACTOR, na qual, para se verificar a adequabilidade do modelo, utilizou-se a medida de adequação da amostra de Kaiser-MeyerOlkin. As variáveis foram selecionadas para compor cada fator pelas suas comunalidades, que representam as proporções da variação das variáveis originais, as quais são explicadas pelo fator comum. $\mathrm{O}$ número de fatores foi definido pelo autovalor, sendo considerados todos os fatores com autovalores superiores a um. As cargas fatoriais foram consideradas significativas a partir de 0,4, e utilizou-se a rotação Promax.

A análise de agrupamento foi empregada como complemento da análise fatorial, tendo em vista melhorar a compreensão dessas relações mediante a formação de grupos que apresentam similaridade dentro de si mesmos e diferenças entre os grupos. Foi utilizado o método hierárquico de Ward, baseado na distância euclidiana, para estimar as médias padronizadas dos grupos, sendo estas, posteriormente, transformadas nas médias originais para cada grupo. A análise de agrupamento foi confirmada pela análise canônica (PROC CANDISC), que demonstra graficamente a distância entre os grupos, e pela análise discriminante (PROC DISCRIM), por meio do método STPEDISC, para selecionar as variáveis responsáveis pela diferenciação dos grupos. As médias padronizadas dos três grupos formados foram comparadas, a fim de se identificar a diferença entre os grupos, utilizando-se a análise de variância multivariada (MANOVA), pelo PROC GLM, com médias de grupos comparadas pelo teste de Tukey-Kramer, ao nível de significância de $5 \%$.

Antes do início do estudo, todos os protocolos foram aprovados pelo Comitê de Ética em Experimentação Animal da Universidade de Santa Catarina, conforme protocolo número 1.64.13.

\section{RESULTADOS}

Os valores médios e a dispersão dos indicadores da profundidade do úbere, da produção de leite, do número de ordenhas diárias, da saúde da glândula mamária (ECS) e da eficácia de limpeza de tetos constam na Tab. 1 .

$\mathrm{Na}$ análise fatorial (Tab. 2), os quatro primeiros fatores, abrangendo as variáveis profundidade do úbere, produção de leite, número de ordenhas diárias, saúde da glândula mamária e indicadores de limpeza dos tetos antes e após a higienização automática, explicaram $78,1 \%$ da variabilidade acumulada dos dados. $\mathrm{O}$ fator 1 , produção de leite, é representado pela relação positiva entre produção de leite e número de ordenhas diárias, os quais estão inversamente relacionados com a profundidade do úbere e a diferença do ELTT. Portanto, as vacas mais produtivas apresentam maior número de ordenhas diárias e, consequentemente, têm úbere mais profundo e menor efetividade de limpeza dos tetos. $\mathrm{O}$ fator 2, que corresponde à efetividade da limpeza física dos tetos com tolhas umedecidas, apresentou relação positiva entre a sujidade dos tetos antes e após a limpeza automática, indicando que tetos mais sujos antes da ordenha apresentam menor efetividade de limpeza. O fator 3, denominado de efetividade da limpeza bacteriológica, relacionou positivamente a CBT da superfície dos tetos antes da limpeza automática com a efetividade de higienização da 
superfície dos tetos após a limpeza automática. Por último, o fator 4 , que corresponde à saúde da glândula mamária, associou inversamente a profundidade do úbere com o ECS, ou seja, vacas com úberes mais profundos apresentaram maior ECS.

Tabela 1. Análise descritiva dos dados das vacas incluídas neste estudo $(\mathrm{n}=20)$

\begin{tabular}{|c|c|c|c|c|c|}
\hline Variável & Unidade & Média & $\mathrm{DP}^{(1)}$ & Mínimo & Máximo \\
\hline Profundidade úbere & Escore & 2,50 & 1,12 & 1,00 & 4,00 \\
\hline Ordenha dia & Número & 2,36 & 0,37 & 1,7 & 3,71 \\
\hline Produção leite & $\mathrm{kg} / \mathrm{dia}$ & 36,24 & 8,21 & 19,36 & 57,78 \\
\hline $\mathrm{ECS}^{(2)}$ & $\log ^{2}$ & 2,46 & 2,14 & $-1,64$ & 6,98 \\
\hline ELTT antes $^{(3)}$ & Escore & 2,48 & 0,51 & 1,50 & 3,50 \\
\hline ELTT depois $^{(4)}$ & Escore & 1,31 & 0,55 & 0,00 & 2,50 \\
\hline Diferença de $\mathrm{ELTT}^{(5)}$ & Escore & 1,17 & 0,47 & 0,00 & 2,00 \\
\hline CBT $^{3}$ antes $^{(6)}$ & $\log _{10} \mathrm{ufc} / \mathrm{mL}$ & 2,32 & 0,52 & 0,85 & 3,26 \\
\hline CBT depois $^{(7)}$ & $\log _{10} \mathrm{ufc} / \mathrm{mL}$ & 1,93 & 0,63 & 0,70 & 3,11 \\
\hline Diferença da $\mathrm{CBT}^{(8)}$ & $\log _{10} \mathrm{ufc} / \mathrm{mL}$ & 0,39 & 0,64 & $-1,10$ & 1,38 \\
\hline
\end{tabular}

${ }^{(1)} \mathrm{DP}$ - desvio-padrão. ${ }^{(2)} \mathrm{ECS}$ - escore de células somáticas = log2 (CCS/100) + 3 (Ali e Shook, 1980). ${ }^{(3)}$ ELTT antes - escore de limpeza de tetos com toalha umedecida antes da limpeza: média de dois tetos contralaterais. ${ }^{(4)}$ ELTT depois - escore de limpeza de tetos com toalha umedecida após a limpeza: média de dois tetos contralaterais. ${ }^{(5)}$ Diferença de ELTT - diferença da limpeza dos tetos avaliada com toalhas umedecidas antes e após a limpeza: média de dois tetos contralaterais. ${ }^{(6)} \mathrm{CBT}$ antes - contagem bacteriana total da superfície do teto antes da limpeza: média de dois tetos contralaterais. ${ }^{(7)} \mathrm{CBT}$ depois - contagem bacteriana total da superfície do teto após a limpeza: média de dois tetos contralaterais. ${ }^{(8)}$ Diferença da CBT - diferença da contagem bacteriana total dos tetos avaliada com swabs antes e após a limpeza: média de dois tetos contralaterais.

Tabela 2. Cargas fatoriais, comunalidades e percentual de variância da profundidade do úbere, da produção de leite, das ordenhas diárias e dos indicadores de efetividade de limpeza dos tetos e da saúde da glândula mamária

\begin{tabular}{cccccc} 
Variáveis & \multicolumn{4}{c}{ Fatores $^{(1)}$} & \multirow{2}{*}{ Comunalidades } \\
\cline { 2 - 5 } & 1 & 2 & 3 & 4 & 74,8 \\
Ordenha/dia (número) & 0,8843 & $-0,0308$ & $-0,0270$ & $-0,2047$ & 74,3 \\
Produção leite (kg/dia) & 0,8722 & 0,0558 & 0,0063 & $-0,0424$ & 70,3 \\
Profundidade úbere & $-0,6358$ & 0,0129 & 0,0096 & $-0,4194$ & 78,6 \\
ELTT antes $^{(2)}$ & 0,1942 & 0,8823 & 0,0436 & 0,0801 & 73,6 \\
Diferença de ELTT $^{(3)}$ & $-0,2825$ & 0,7322 & $-0,0516$ & $-0,1722$ & 71,8 \\
Diferença CBT (ufc/mL) $^{(4)}$ & $-0,0439$ & $-0,1320$ & 0,8355 & $-0,1151$ & 69,6 \\
CBT antes (ufc/mL) $^{(5)}$ & 0,0171 & 0,1435 & 0,8120 & 0,0983 & 89,2 \\
ECS (log ${ }^{(6)}$ & $-0,1248$ & $-0,0179$ & $-0,0126$ & 0,9620 & \\
\%Variância $^{(6)}$ & 28,5 & 17,9 & 16,9 & 11,8 & \\
\hline
\end{tabular}

${ }^{(1)}$ Fatores: 1 - produção de leite, 2 - efetividade da limpeza física, 3 - efetividade da limpeza bacteriológica e 4 saúde da glândula mamária, formados pela análise fatorial. ${ }^{(2)}$ ELTT antes - escore de limpeza de tetos com toalha umedecida antes da limpeza: média de dois tetos contralaterais. ${ }^{(3)}$ Diferença de ELTT - diferença da limpeza dos tetos avaliada com toalhas umedecidas antes e após a limpeza: média de dois tetos contralaterais. ${ }^{(4)}$ Diferença da CBT - diferença da contagem bacteriana total dos tetos avaliada com swabs antes e após a limpeza: média de dois tetos contralaterais. ${ }^{(5)} \mathrm{CBT}$ antes - contagem bacteriana total dos tetos antes da limpeza: média de dois tetos contralaterais. ${ }^{(6)}$ ECS - escore de células somáticas $=\log 2(C C S / 100)+3$ (Ali e Shook, 1980).

A análise canônica conseguiu capturar a diferença entre os grupos formados pela análise de agrupamento e tem a finalidade de demonstrar, graficamente, as distâncias utilizadas na separação dos grupos (Fig. 1). Neste estudo, foram identificados três grupos. O grupo 1 diferiu do 2 nas variáveis profundidade do úbere, produção de leite, número de ordenhas diárias, ECS, ELTT depois, CBT depois e diferença de CBT. Os grupos 1 e 2 diferenciam-se do grupo 3 em razão das variáveis profundidade do úbere, produção de leite, número de ordenhas diárias, ECS, ELTT antes, ELTT depois, CBT antes, CBT depois e diferença de CBT. 


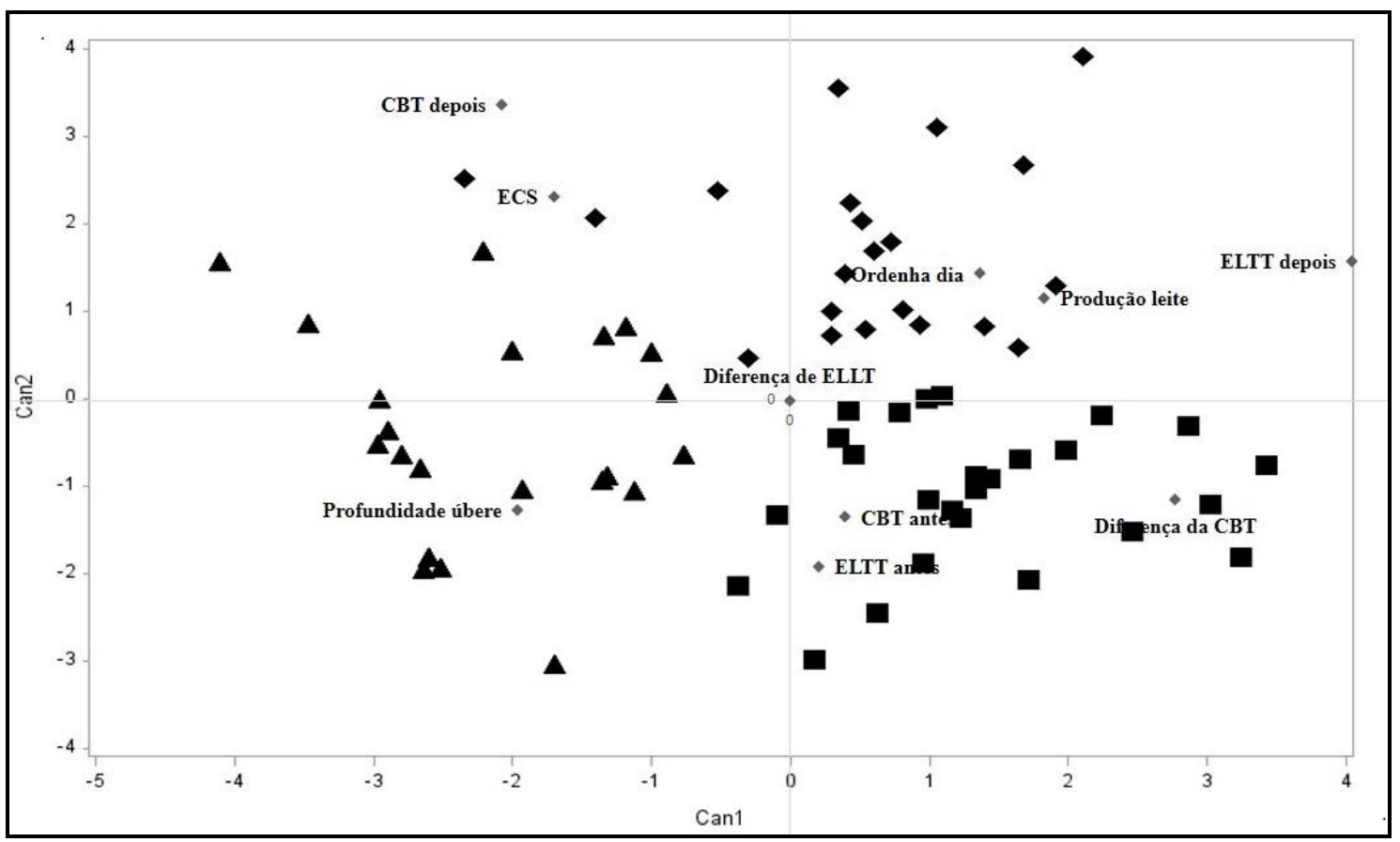

Figura 1. Representação gráfica obtida por meio da análise canônica das características de cada grupo de vacas conforme a profundidade do úbere. Grupo $1(\boldsymbol{\square})$; grupo 2 ( $\mathbf{\Delta})$; grupo $3(\diamond)$.

Dentro da análise de agrupamento, foi realizada a análise discriminante, pelo método STEPDISC, a qual é responsável por selecionar as variáveis que compuseram o modelo final $(\mathrm{P}<0,0001)$. As variáveis profundidade do úbere, número de ordenhas/dia, produção de leite, ECS, ELTT depois, CBT depois e diferença da CBT foram determinantes na diferenciação dos grupos. Foram formados três grupos, sendo o grupo 1 representado, em média, por vacas com profundidade do úbere normal, número de ordenhas diárias, produção de leite e diferença do ELTT intermediários, menor ECS e CBT depois da limpeza e maior diferença de CBT. Isso demonstrou que vacas com profundidade do úbere normal apresentam melhor efetividade de limpeza e higienização dos tetos e melhor saúde da glândula mamária. O grupo 3 apresentou vacas com úbere profundo (escore 1,55), produção de leite, número de ordenhas diárias e ECS maiores, porém menor efetividade de limpeza e higienização dos tetos. Portanto, o aumento da profundidade do úbere tem influência negativa sobre a efetividade de limpeza e higienização dos tetos, bem como sobre a saúde da glândula mamária em SOR. O grupo 2 foi caracterizado por vacas com profundidade do úbere rasa, produção de leite, número de ordenhas diárias e ELTT antes e depois da higienização menores e maior diferença no ELTT, o que indica que este grupo tem melhor efetividade de limpeza dos tetos.

\section{DISCUSSÃO}

Considerando-se a metodologia descrita por Hovinen (2009), antes da limpeza automática, os tetos estavam levemente sujos (ELTT $=2,48$ ), com 10 a $20 \%$ da superfície suja, enquanto depois da limpeza encontravam-se levemente limpos (ELTT=1,31), com menos de $10 \%$ da superfície suja (Tab. 1). Essa diferença do ELTT antes e depois $(1,17)$ permite concluir que a efetividade na limpeza dos tetos depende do estado de limpeza deles quando as vacas chegam à estação de ordenha. Como o ELTT é um indicador da limpeza física dos tetos, a CBT é fundamental para avaliar não só a limpeza física como também a contaminação da superfície deles, pois a limpeza física pode não ser um bom indicador da qualidade microbiológica dela.

Foi observada uma redução na média da CBT da superfície dos tetos depois da limpeza automática $\left(\log _{10} \mathrm{ufc} / \mathrm{mL}=1,93\right)$ em relação à contagem antes da limpeza automática $\left(\log _{10} \mathrm{ufc} / \mathrm{mL}=\right.$ 2,32). A CBT após a limpeza automática ficou dentro do limite $\left(\log _{10} \mathrm{ufc} / \mathrm{mL}<2\right)$ descrito por 
Knappstein et al. (2002) para classificar os tetos como limpos. No estudo de Knappstein et al. (2004), a CBT inicial dos tetos, antes da limpeza automática, foi significativa para a efetividade da limpeza. Segundo esses autores, a contagem bacteriana dos tetos, em alguns rebanhos, aumentou após a limpeza automática devido a falhas dos dispositivos de limpeza e, particularmente, nos casos de baixa contaminação dos tetos antes da limpeza automática.

De acordo com as análises fatorial (Tab. 2) e de agrupamento (Fig. 1 e Tab. 3), quanto mais profundo o úbere, maior a produção de leite e, consequentemente, maior o número de ordenhas diárias e pior a saúde da glândula mamária. Os úberes profundos tiveram uma menor efetividade na limpeza dos tetos avaliada por meio da diferença da ELTT (Tab. 2). Portanto, a profundidade do úbere, além de interferir na produção e qualidade do leite, interferiu também no grau de sujidade dos tetos. Vacas com úberes profundos apresentam risco mais elevado de novas IIM e de infecções crônicas, e vacas com úberes sujos apresentam maior risco de ocorrência de novos casos de mastite subclínica (Cardozo et al., 2015).

Tabela 3. Análise de agrupamentos referente à profundidade do úbere, à produção de leite, às ordenhas/dia, ao escore de células somáticas, aos indicadores de limpeza dos tetos e ao número de observações por grupo ${ }^{(1)}$

\begin{tabular}{|c|c|c|c|c|c|}
\hline \multirow{2}{*}{ Variáveis } & \multirow{2}{*}{ Unidade } & \multicolumn{3}{|c|}{ Grupos $^{(2)}$} & \multirow{2}{*}{$\mathrm{P}>\mathrm{F}$} \\
\hline & & 1 & 2 & 3 & \\
\hline Profundidade úbere & Escore & $2,61 \mathrm{a}$ & $3,15 \mathrm{a}$ & $1,55 \mathrm{~b}$ & $<0,0001$ \\
\hline Ordenha dia & Número & $2,38 \mathrm{~b}$ & $2,09 \mathrm{c}$ & $2,66 \mathrm{a}$ & $<0,0001$ \\
\hline Produção leite & $\mathrm{kg} / \mathrm{dia}$ & $35,94 \mathrm{~b}$ & $31,06 \mathrm{c}$ & $42,57 \mathrm{a}$ & $<0,0001$ \\
\hline $\mathrm{ECS}^{(3)}$ & $\log ^{2}$ & $1,46 \mathrm{~b}$ & $2,83 \mathrm{a}$ & $3,39 \mathrm{a}$ & $=0,0029$ \\
\hline ELTT antes ${ }^{(4)}$ & Escore & $2,66 \mathrm{a}$ & $2,28 \mathrm{~b}$ & $2,45 \mathrm{ab}$ & $=0,0159$ \\
\hline ELTT depois $^{(5)}$ & Escore & $1,52 \mathrm{a}$ & $0,83 \mathrm{~b}$ & $1,59 \mathrm{a}$ & $<0,0001$ \\
\hline Diferença de $\mathrm{ELLT}^{(6)}$ & Escore & $1,15 \mathrm{~b}$ & $1,44 \mathrm{a}$ & $0,86 \mathrm{c}$ & $<0,0001$ \\
\hline CBT antes ${ }^{(7)}$ & $\log _{10} \mathrm{ufc} / \mathrm{mL}$ & 2,37 & 2,30 & 2,28 & $=0,8203$ \\
\hline CBT depois ${ }^{(8)}$ & $\log _{10} \mathrm{ufc} / \mathrm{mL}$ & $1,42 \mathrm{~b}$ & $2,16 \mathrm{a}$ & $2,33 \mathrm{a}$ & $<0,0001$ \\
\hline Diferença da $\mathrm{CBT}^{(9)}$ & $\log _{10} \mathrm{ufc} / \mathrm{mL}$ & $0,71 \mathrm{a}$ & $-0,07 b$ & $-0,19 b$ & $<0,0001$ \\
\hline Número de observações & & 31 & 27 & 22 & \\
\hline
\end{tabular}

${ }^{(1)}$ Médias na mesma linha, seguidas por letras distintas, diferem entre si pelo teste de Tukey a 5\% de significância. ${ }^{(2)}$ Grupos formados pela análise de agrupamento $(1$ - úbere intermediário/normal, 2 - úbere raso e 3 - úbere profundo). ${ }^{(3)} \mathrm{ECS}-$ escore de células somáticas $=\log 2(\mathrm{CCS} / 100)+3$ (Ali e Shook, 1980). ${ }^{(4)}$ ELTT antes - escore de limpeza de tetos com toalha umedecida antes da limpeza: média de dois tetos contralaterais. ${ }^{(5)}$ ELTT depois - escore de limpeza de tetos com toalha umedecida após a limpeza: média de dois tetos contralaterais. ${ }^{(6)}$ Diferença de ELTT diferença da limpeza dos tetos avaliada com tolhas umedecidas antes e após a limpeza: média de dois tetos contralaterais. ${ }^{(7)} \mathrm{CBT}$ antes - contagem bacteriana total da superfície do teto antes da limpeza: média de dois tetos contralaterais. ${ }^{(8)} \mathrm{CBT}$ depois - contagem bacteriana total da superfície do teto após a limpeza: média de dois tetos contralaterais. ${ }^{(9)}$ Diferença da CBT - diferença da contagem bacteriana total dos tetos avaliada com swabs antes e após a limpeza: média de dois tetos contralaterais.

Em SOR, deve ser dada maior importância na seleção de vacas com conformação de úbere mais adequado ao sistema. O grupo 1 , composto por vacas com úberes com profundidade intermediária/normal (Tab. 3), tendeu a ter médias de produção de leite $(35,94 \mathrm{~kg} / \mathrm{dia})$ e de ordenhas diárias $(2,36)$ próximas à média do rebanho (Tab. 1), além de menor ECS e maior efetividade na limpeza dos tetos avaliada via swabs (Tab. 3). Portanto, vacas com úberes intermediários (profundidade um pouco acima do jarrete) apresentaram produção de leite, saúde da glândula mamária, contaminação dos tetos e, consequentemente, conformação mais adequadas ao SOR. O grupo 2, representado por vacas com úberes menos profundos (pequenos e rasos) (Tab. 3), produziu menos leite e com qualidade inferior quando comparado com o grupo 1, apesar de apresentar maior efetividade de limpeza dos tetos avaliada por meio do ELTT. Contudo, apresentou CBT da superfície dos tetos e saúde da glândula mamária igual às vacas com úberes profundos (grupo 3). Úberes mais profundos apresentaram maior sujidade dos tetos antes da limpeza (grupos 1 e 3) e menor efetividade na limpeza deles avaliada via ELTT 
(grupo 3). No estudo de DeVries et al. (2012), as vacas com úberes mais profundos apresentaram tetos mais sujos devido à proximidade com o piso. Além disso, esses autores observaram que essas vacas, por produzirem mais leite, permaneceram mais tempo em pé para se alimentarem, expondo o úbere ao esterco dos corredores e da área de alimentação.

Tanto a limpeza dos tetos depois da higienização pelo braço robótico quanto a efetividade da limpeza, avaliadas via swabs e com toalhas umedecidas, dependem do escore de limpeza dos tetos quando as vacas entram na unidade de ordenha (Tab. 2). Isso demonstrou a importância do ambiente da vaca para a qualidade higiênica da ordenha em SOR. Portanto, a limpeza dos tetos ao chegar à ordenha contribuiu mais do que a própria limpeza antes da ordenha. Para aumentar a limpeza dos tetos antes da entrada na estação de ordenha, a gestão da higiene das camas e do piso dos corredores precisa ser eficiente, pois, como demonstrado neste estudo, o dispositivo de limpeza não remove toda a sujidade dos tetos. A fim de superar esse problema, a gestão da higiene deve ser melhorada, não apenas com foco na higiene dos tetos, mas também na manutenção de elevados padrões de higiene nas camas e no piso dos corredores (Svennersten-Sjaunja e Pettersson, 2008).

Na Tab. 3, é possível observar que os tetos com maior CBT apresentaram maior CCS (grupos $2 \mathrm{e}$ 3). A higiene pobre dos tetos está associada à alta incidência de mastite clínica (Breen et al., 2009) e à elevada CCS (Dohmen et al., 2010). Conforme Sant'anna e Paranhos da Costa (2011), uma possível explicação para a associação entre higiene da vaca leiteira e CCS no leite seria a exposição reduzida dos animais limpos a patógenos ambientais. Em um estudo realizado nos Estados Unidos, com 1.093 vacas em oito fazendas, foram observadas relações significativas entre a CCS e o escore de higiene da vaca composto por higiene do úbere, pernas e pés (Reneau et al., 2005). Dohmen et al. (2010) também relacionaram positivamente a média anual de CCS do leite individual com a proporção de vacas com tetos, úbere, coxas e pernas sujos antes da ordenha. A higiene da vaca também foi associada ao tempo em que ela fica deitada ou em pé e à limpeza do ambiente (DeVries, 2012).

Considerando-se os aspectos de funcionalidade e sanidade da glândula mamária, a conformação de úbere mais adequada ao SOR coincide com a classificação linear para tipo utilizada no Brasil (extremos biológicos de 1 a 9), onde a profundidade de úbere ideal (piso) se localiza logo acima do jarrete (pontuação 5) (Atualização..., 2010). Segundo Carlström (2014), existe alta herdabilidade e correlações genéticas entre as características de conformação de úbere e o posicionamento dos tetos medidos pelo SOR e as avaliadas na classificação linear para tipo. Assim, seria possível utilizar informações das coordenadas dos tetos e do úbere para substituírem ou serem utilizadas como um complemento às classificações para avaliação genética de conformação do úbere e colocação dos tetos.

$\mathrm{Na}$ avaliação visual e/ou bacteriológica, a limpeza automática dos tetos no SOR é menos efetiva que a limpeza manual (Knappstein et al., 2004). Um dos problemas potenciais no SOR é a incapacidade de distinguir entre um teto sujo ou limpo (Jacobs e Siegford, 2012). Como o processo é padronizado e não pode ser ajustado conforme a sujidade, não há dispositivo disponível para distinguir entre tetos sujos e limpos ou para monitorar a efetividade da limpeza (Hovinen, 2009). Portanto, para evitar novos casos de IIM e/ou a elevação da CCS após a introdução do SOR, além da limpeza das camas e dos corredores, a qualidade microbiológica da água utilizada na estação de ordenha, em especial na limpeza dos tetos, deve ser monitorada periodicamente e, se necessário, a água deve ser tratada. Ênfase deve ser dada, também, à eficácia dos produtos utilizados no pré-dipping, observando-se tempo e forma de aplicação pelo braço robótico, a fim de se manter a CCS em níveis aceitáveis. Isso porque, segundo Dohmen et al. (2010), relações positivas foram observadas entre a porcentagem média anual de novos casos com alta CCS e a proporção de vacas com tetos sujos antes da ordenha, a proporção de ordenhas em que os tetos não foram cobertos com o spray de desinfecção após a ordenha e a proporção de vacas com úberes e coxas sujos. 


\section{CONCLUSÕES}

Fazendas que pretendem introduzir o SOR devem, primeiramente, trabalhar na seleção e padronização da conformação do úbere, sendo recomendadas vacas com úbere com profundidade um pouco acima do jarrete. $\mathrm{O}$ impacto da utilização do SOR na CBT dos tetos está relacionado à condição de limpeza dos tetos pré-ordenha, em que a condição de ambiência das vacas é fundamental para a obtenção de um leite com baixa contaminação microbiológica.

\section{REFERÊNCIAS}

ALI, A.K.A.; SHOOK, G.E. An optimum transformation for somatic cell concentration in milk. J. Dairy Sci., v.63, p.487-490, 1980.

ATUALIZAÇÃO do sistema de avaliação para classificação para tipo: avaliação da conformação ideal. São Paulo: ABCBRH, 2010.

BREEN, J.E.; GREEN, M.J.; BRADLEY, A.J. Quarter and cow risk factors associated with the occurrence of clinical mastitis in dairy cows in the United Kingdom. J. Dairy Sci., v.92, p.25512561, 2009.

CARDOZO, L.L.; THALER NETO, A.; PICININ, L.C.A. et al. Risk factors for the occurrence of new and chronic cases of subclinical mastitis in dairy herds in southern Brazil. J. Dairy Sci., v.98, p.7675-7685, 2015.

CARLSTRÖM, C. Genetic variation of in-line recorded milkability traits and associations with udder conformation and health in Swedish dairy cattle. 2014. 55f. Thesis (Doctoral) - Swedish University of Agricultural Sciences, Uppsala, SWE.

DeVRIES, T.J.; AARNOUDSE, M.G.; BARKEMA, H.W.et al. Associations of dairy cow behavior, barn hygiene, cow hygiene, and risk of elevated somatic cell count. J. Dairy Sci., v.95, p.5730-5739, 2012.

DOHMEN, W.; NEIJENHUIS, F.; HOGEVEEN, H. Relationship between udder health and hygiene on farms with an automatic milking system. J. Dairy Sci., v.93, p.4019-4033, 2010.
HOVINEN, M. Udder health of dairy cows in automatic milking. 2009. 94f. Dissertation (Master) - Faculty of Veterinary medicine, University of Helsinki, Helsinki, FIN.

HOVINEN, M.; AISLA, A.M.; PYORÄLÄ, S. Visual detection of technical success and effectiveness of teat cleaning in two automatic milking systems. J. Dairy Sci., v.88, p.33543362, 2005.

HOVINEN, M.; PYÖRÄLÄ, S. Invited review: udder health of dairy cows in automatic milking. J. Dairy Sci., v.94, p.547-562, 2011.

INTERNATIONAL Dairy Federation. Milk enumeration of somatic cells - part 2: guidance on the operation of fluoro-opto-electronic counters. ISO 13366- 2. Brussels, Belgium, 2006. p.15. (International Dairy Federation 1482).

INTERNATIONAL Dairy Federation. Whole milk determination of milk fat, protein and lactose content. Guide fir the operation of midinfra-redinstruments. Brussels, Belgium: IDF, 1996. p.12. (IDF Standard 141 B).

JACOBS， J.A.; SIEGFORD， J.M. Invited review: the impact of automatic milking systems on dairy cow management, behavior, health, and welfare. J. Dairy Sci., v.95, p.2227-2247, 2012.

JANZEKOVIC, M.; BRUS, M.; MURSEC, B. Mastitis detection based on electric conductivity of milk. J. Achiev. Mater. Manuf. Eng., v.34, p.39-46, 2009.

KLAAS, I.C. et al. Cow related risk factors for milk leakage. J. Dairy Sci., v.88, p.128-136, 2005.

KNAPPSTEIN, K.; ROTH, N.; SLAGHUIS, B.A. et al. Effectiveness of automatic cleaning of udder and teats and effects of hygiene management: protocol for evaluation of teat cleaning systems: report eu project implications of the introduction of automatic milking on dairy farms. 2002. p.33. Available in: <http://www.automaticmilking.nl>. Accessed in: 2 Dec. 2014. 
KNAPPSTEIN, K.; ROTH, N.; WALTE, H.G. et al. Effectiveness of automatic cleaning of udder and teats and effects of hygiene management: report on effectiveness of cleaning procedures applied in different automatic milking systems: report eu project implications of the introduction of automatic milking on dairy farms. 2004. p.31. Available in: <http://www.automaticmilking.nl>. Accessed in: 30 Jul. 2014.

MAGNUSSON, M. Bacillus cereus in the housing environment of dairy cows. contamination routes, effect of teat cleaning, and measures to improve hygiene in the cubicles and alleys. 2007. 42f. Thesis (Doctoral) - Swedish University of Agricultural Sciences, Alnarp, SWE.

MICROBIOLOGICAL procedures for the diagnosis of bovine udder infection and determinacion of milk qualiry. 4.ed. Verona, WI: National Mastitis Council, 2004. p.47.
MILLER, R.H. et al. Variation in distances among teats of Holstein cows: implications for automated milking. J. Dairy Sci., v.78, p.14561462, 1995.

RENEAU, J.K.; SEYKORA, A.J.; HEINS, B.J. et al. Association between hygiene scores and somatic cell scores in dairy cattle. J. Am. Vet. Med. Assoc., v.227, p.1297-1301, 2005.

SANT'ANNA, A.C.; PARANHOS DA COSTA, M.J.R. The relationship between dairy cow hygiene and somatic cell count in milk. J. Dairy Sci., v.94, p.3835-3844, 2011.

SAS/STAT, version 9.2. Cary: SAS, 1999. OnlineDoc.

SVENNERSTEN-SJAUNJA,

K.M.; PETTERSON, G. Pros and cons of automatic milking in Europe. J. Anim. Sci., v.86, Suppl.1, p.37-46, 2008. 